\title{
Isolation of Thymidine-Requiring Variants from Rat Nerve-Like Cells
}

\author{
Kazuhiro Ishii \\ Institute for Virus Research, Kyoto University, Sakyo-ku, Kyoto 606, Japan
}

Key words: pyrimidine metabolisms/nẹrite outgrowth/db-cAMP

\begin{abstract}
Thymidine auxotrophs (B3T) of rat nerve-like cells (B103) were isolated. B103 cells were preincubated in a thymidine medium and mutagenized with $\mathrm{N}$-methyl-N'-nitro- $\mathrm{N}$-nitrosoguanidine (MNNG). Afterward, cells were incubated in a medium supplemented with dialyzed fetal calf serum and then treated with 5fluorodeoxyuridine for $24 \mathrm{~h}$. Next, cells were grown in a thymidine medium for twenty days. Thymidine auxothrophs were thus obtained and one clone of them was designated B3T cells. The modal number of chromosomes in B3T cells was 85 . Growth tests revealed the following interesting facts: (1) The medium containing pyrazofurin and uridine could not support the growth of B3T cells, but the addition of thymidine to such a medium enabled cells to grow. (2) Even deoxyuridine supported the growth of B3T cells when added to the medium of pyrazofurin and uridine. These findings suggest that the catalytic ability of thymidylate synthetase in B3T cells may have decreased, probably due to the decreased affinity of the enzyme molecules to the substrate (dUMP), and that thymidine kinase activity was high enough to support the growth of B3T cells. B3T cells have maintained the ability to differentiate and extend neurites in response to dibutyryl-cyclic AMP as also demonstrated in wild cells (B103). B3T cells will be available for genetical and molecular biological studies of neuronal cells.
\end{abstract}

5 -fluorodeoxyuridine (FdU) is a substrate analogue for thymidine kinase $(4,5)$. Its monophosphate, 5fluorodeoxyuridylate (FdUMP) inhibits the activity of thymidylate synthetase which converts deoxyuridylate (dUMP) to thymidylate (TMP) $(7,14,16,20)$. Therefore, when cultured in a medium with FdU, cells stop proliferating due to TMP starvation which leads to cell death. However, when continuously cultured in a medium with FdU for a long period of time, some cells acquire resistance to the drug and show good growth in such a medium. The resistance is due to genetic changes in the enzymes involved in the metabolism of FdU. For example, in one case, cells were found to overproduce thymidylate synthetase through amplification of the genes $(8,11,15)$, and in another case, cells had low activities of thymidine kinase $(4,18)$.

In the course of our studies on neuronal differentiation, there occurred the necessity to develop thymidine auxotrophic clones of rat nerve-like cells. Since the above-mentioned method did not seem to be available for isolation of such clones, we have applied a single-hit method (12) and successfully isolated thymidine auxotrophs. I describe here the method and the physiological properties of the variant.

\section{MATERIALS AND METHODS}

Cell culture. A rat nerve-like cell line (B103) was a gift of
Dr. David Schubert (17). Cells were cultured in DulbeccoVogt modification of Eagle MEM (Nissui) supplemented with $10 \%$ fetal calf serum (FCS) (MAB). For drung tests, cells were inoculated at the cell density of $1-2 \times 10^{4} / 0.5 \mathrm{ml} /$ well in a 24 well plate (Corning). For cloning culture, cells were inoculated at 100 cells/60-mm dish (Corning) and cultured for 10 days without medium changes.

Isolation of thymidine auxotrophs. Cells were grown in a medium containing $16 \mu \mathrm{M}$ thymidine for 6 days. After cell dissociation, cells were inoculated in a thymidine-medium at $10^{6}$ cells per $60-\mathrm{mm}$ dish and cultured for $24 \mathrm{~h}$. For mutagenization (6), cells were treated with $\mathrm{N}$-methyl- $\mathrm{N}^{\prime}$-nitro-N-nitrosoguanidine (MNNG) $(10 \mu \mathrm{M})$ at $37^{\circ} \mathrm{C}$ for $5 \mathrm{~h}$. After washing, cells were grown for 3 days in a thymidine medium to fix the mutated changes. Then, cells were dissociated and the cell yield was $5.5 \times 10^{6}$ cells $/$ dish, and inoculated at $2 \times 10^{5} / 60$ $\mathrm{mm}$ dish in the medium supplemented with dialyzed fetal calf serum $(10 \%)$. After 4-h incubation, cells were washed with the medium of dialyzed FCS and incubated in a medium containing dialyzed FCS, $1 \mathrm{mM} \mathrm{FdU}$ and $0.1 \mathrm{mM}$ uridine for $24 \mathrm{~h}$. After washing, cells were grown in a thymidine medium for 20 days. The culture medium was changed twice a week.

Karyotype analysis. Chromosome preparation was carried out by the conventional method. Briefly, cells were grown in dT-medium and treated with colchicine $(0.1 \mu \mathrm{M})$ for $2 \mathrm{~h}$. Cells were dissociated by the treatment with trypsin/EDTA and after washing with phosphate-buffered saline (PBS), incubated in a one-fourth dilution of PBS at $35^{\circ} \mathrm{C}$ for $15 \mathrm{~min}$ for 
Table I. COLONY FORMATION IN VARIOUS MEDia.

\begin{tabular}{lcr}
\hline Culture Medium & B3T Cells & B103 Cells \\
\hline Regular Medium (RM) & $6,6,8^{*}(7)$ & $62,84,100(82)$ \\
Growth Medium (RM +dT) & $32,21,20(24)$ & $42,66,50(53)$ \\
Selection Medium (SM) (Dialyzed Serum) & $0,0,0(0)$ & $110,50,60(73)$ \\
SM+dT $(16 \mu \mathrm{M})$ & $23,29,24(25)$ & \\
\hline
\end{tabular}

Cells were inoculated at 100 cells $/ 60-\mathrm{mm}$ dish in various media and cultured for 14 days.

* The number of colonies per dish. The parentheses show the average number.

\# dT: Thymidine.

the hypotonic treatment. Then, cells were fixed with methanol/acetic acid (3:1 in volume), and placed on glass slides. Fixed cells were stained with Giemsa solution.

Reagents. The drugs were dissolved in distilled water: $\mathrm{N}^{6}$, $\mathrm{O}^{2}$-dibutyryl-adenosine- $3^{\prime}, 5^{\prime}$-cyclic monophosphate, sodium salt (db-cAMP) (Sigma) $(100 \mathrm{mM})$, pyrazofurin (pyrazomycin) (Calbiochem) (10 mM), 5-fluorodeoxyuridine (Sigma), thymidine, uridine, and cytidine (Kohjin). N-methyl-N'-nitro$\mathrm{N}$-nitrosoguanidine (MNNG) (Nakaraitesque) was dissolved in $50 \mathrm{mM}$ acetate buffer $/ \mathrm{pH} 5.0$.

\section{RESULTS}

Isolation of thymidine-requiring variants. To obtain thymidine-auxotrophic clones, cells were mutagenized with MNNG and treated under the absence of thymidine with a high does of FdU ( $1 \mathrm{mM})$ for only $24 \mathrm{~h}$. The principles of this method are based on three

PYRIMIDINE METABOLISMS

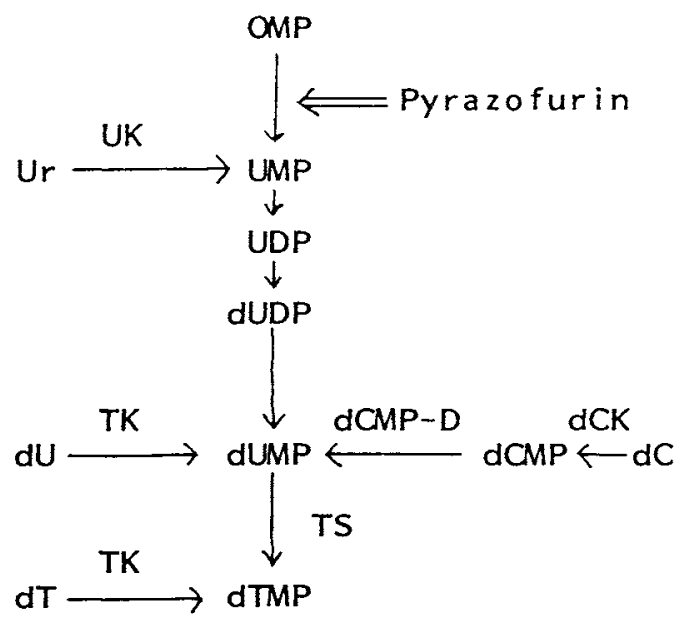

Fig. 1. Pyrimidine metabolisms. Pyrazofurin inhibits the activity of orotidylate (OMP) decarboxylase, leading to the depletion of pyrimidine nucleotides. Abbreviations: dC, deoxycytidine; dU, deoxyuridine; dT, deoxythymidine; Ur, uridine; dCK, dC-kinase; dCMP-D, dCMP-deaminase; TK, thymidine kinase; TS, thymidylate (dTMP) synthetase; UK, uridine kinase. assumptions. (1) As thymidine auxotrophs probably have no or low activities of the enzyme thymidylate synthetase and cannot grow in a medium that does not contain thymidine, the duration of the exposure to the drug should be as short as possible. In this case, it was only $24 \mathrm{~h}$, which is approximately equal to the length of the doubling time in B103 cells. (2) To kill thymidine-nonrequiring cells within $24 \mathrm{~h}$ by treatment with the drug, the concentration of the drug must be high. Actually, in the present expriment, $1 \mathrm{mM}$ FdU was used, whereas the drug is known to be cytotoxic at only $0.1 \mu \mathrm{M}$. (3) Uridine $(0.1 \mathrm{mM})$ was added with FdU to the medium because FdU is catabolized by the enzyme thymidine phosphorylase into 5-fluorouracil, which is also cytotoxic through its phosphorylation into 5-fluorouridylate by the enzyme pyrimidine phosphoribosyltransferase (13).

Thus, four colonies of thymidine auxotrophs were harvested twenty days after culture in the growth medium containing thymidine: the mutation frequency was $10^{-5}$. One of the colonies was set up for cloning culture, and ten days after culture, many clonal colonies were obtained. One of them was designated B3T.

Karyotype. Chromosome numbers of B3T and B103 cells were examined. For B3T cells the modal number of chromosomes was 85 with the range of 78 to 90 (data not shown). In contrast, B103 cells consisted of two cell populations: one of them had 47 chromosomes

Table II. GRowth TESTS FOR B3T CelLS.

\begin{tabular}{lcccc}
\hline \multirow{2}{*}{$\begin{array}{l}\text { The Addition to } \\
\text { dFCS-Medium }\end{array}$} & \multicolumn{5}{c}{ Further Addition to the Medium } \\
\cline { 2 - 4 } & none & $\mathrm{dT}$ & $\mathrm{dU}$ & $\mathrm{dC}$ \\
\hline None & \pm & + & + & \pm \\
Pyrazofurin $(\mathrm{PF})(5 \mu \mathrm{M})$ & - & - & - & - \\
$\mathrm{PF}+\mathrm{Ur}(100 \mu \mathrm{M})$ & - & + & + & \pm \\
\hline
\end{tabular}

Cells were inoculated at $10^{5}$ cells $/ 30-\mathrm{mm}$ dish in various media and cultured for 4 days. (+) The growth was more than $50 \%$ of the control culture which was incubated in the growth medium containing thymidine. $(+/-)$ The growth was $20 \%$ to $50 \%$ of the control. $(-)$ The growth was below $20 \%$ of the control.

Abbreviations: $\mathrm{dFCS}$-medium, the medium containing dialyzed fetal calf serum; dC, deoxycytidine; $\mathrm{dT}$, deoxythymidine; dU, deoxyuridine; $\mathrm{Ur}$, uridine. $\mathrm{dC}$ and $\mathrm{dU}$ were used at the concentration of 100 $\mu \mathrm{M}$, and $\mathrm{dT}$ at $16 \mu \mathrm{M}$. 
as the modal number and the other 90 (data not shown). Whether B3T cells were derived from either of the two cell populations of B103 cells is not known. No marker chromosomes have been identified in B3T cells.

Growth tests. Growth properties of B3T cells were examined. First, to confirm the thymidine requirement for the growth of B3T cells, the plating efficiency of $\mathrm{B} 3 \mathrm{~T}$ cells was determined in various media. Cells were inoculated at 100 cells $/ 60-\mathrm{mm}$ dish and cultured for 10 days. As shown in Table I, the growth of B3T cells was dependent on the presence of thymidine. In contrast, B103 cells showed high plating efficiency even in the medium supplemented with dialyzed serum, though the addition of thymidine to the medium yielded better growth.

Second, the physiological significance of thymidylate synthetase was examined. As shown in Fig. 1, pyrazofu- rin is the potent inhibitor of the orotidylate decarboxylase (9), one of the enzymes involved in pyrimidine de novo synthesis, which converts orotidylate to uridylate (19). In the presence of this drug, cells cannot grow due to pyrimidine nucleotide starvation and eventually die (10). The addition of uridine, however, prevents this metabolic block (10) where uridine is converted to uridylate by the enzyme uridine kinase $(5,22)$. Therefore, this growth system is available for study on the physiological significance of thymidylate synthetase in B3T cells.

As shown in Table II, when B3T cells were cultured under the absence of thymidine in a medium supplemented with dialyzed serum, uridine was not able to rescue $\mathrm{B} 3 \mathrm{~T}$ cells from pyrazofurin toxicity. In contrast, when thymidine was added to the medium, uridine rescued cells from the toxicity. These findings indicate
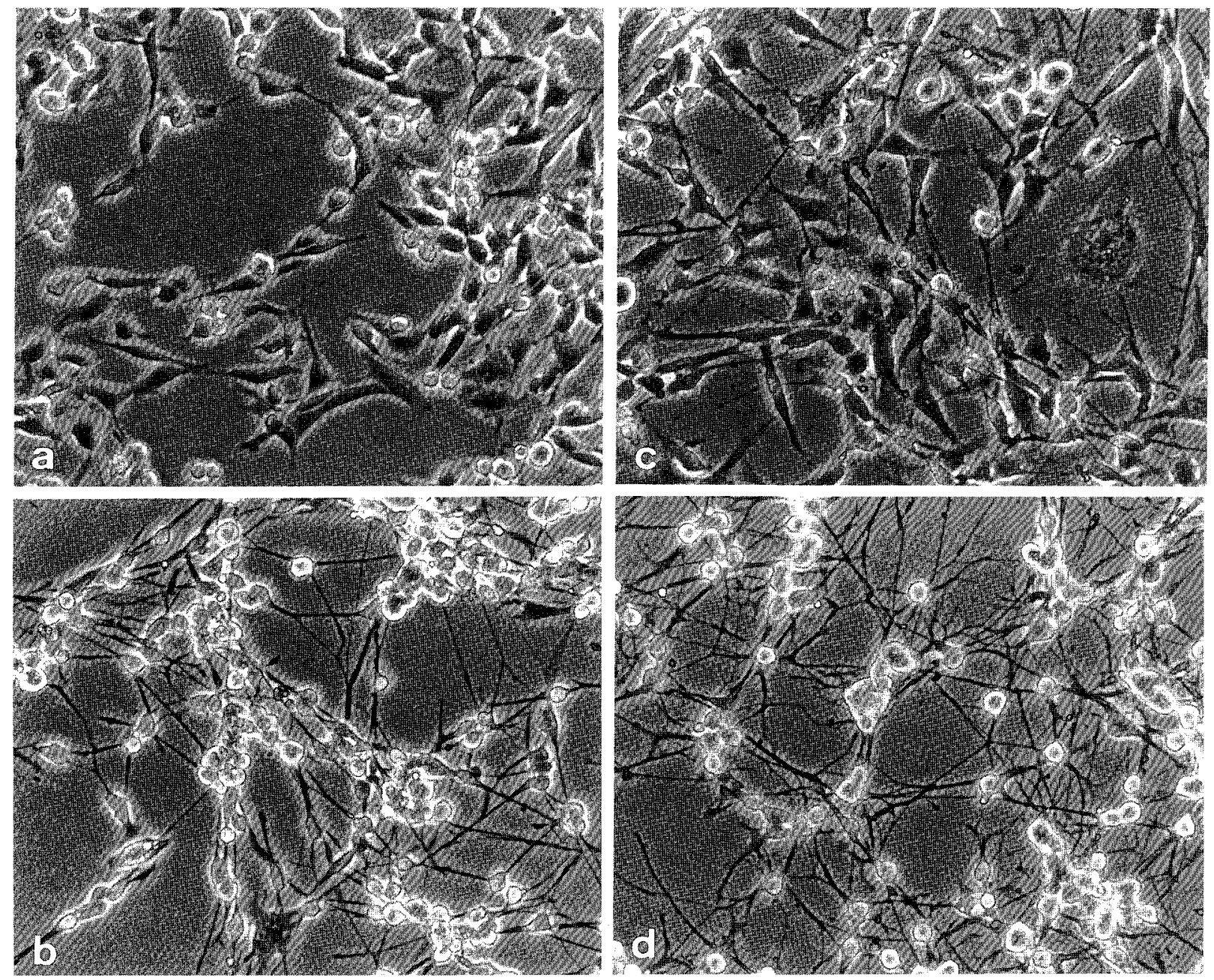

Fig. 2. Induction of neuronal differentiation. Cells were inoculated at $2 \times 10^{4}$ cells/well (24-well plate) and cultured for two days. Cells were added db-cAMP ( $1 \mathrm{mM}$ ), further cultured for one day, and photographed. (a, b) B103 cells; (c.d) B3T cells; (a, c) regular medium; (b, d) dbcAMP added. 
that the activity of thymidylate synthetase in B3T cells cannot support cell growth and that the level of uridine kinase activity is high enough to support the growth of B3T cells.

Interestingly, deoxyuridine (dU) also was able to support the growth of B3T cells in the medium containing pyrazofurin and uridine, while deoxycytidine was less effective (Table 2). These findings suggest that thymidylate synthetase in B3T cells is active enzymologically, though an excess amount of the substrate (dUMP) seems to be needed to support the cell growth.

B103 cells showed good growth in the medium containing pyrazofurin and uridine without addition of thymidine (data not shown).

Neuronal differentiation. Cells of the wild type (B103) are known to differentiate and extend neurites when treated with db-cAMP (17). Whether B3T cells have carried this potency was examined. As shown in Fig. 2, when exposed to db-cAMP, B3T cells differentiated as determined by the formation of long neurites and the rounding of cell bodies. Interestingly, this response was faster in B3T cells than in B103: B3T cells began to extend neurites $30 \mathrm{~min}$ after exposure to the drug, while B103 did so 120 min after the exposure (data not shown).

\section{DISCUSSION}

Thymidine auxotrophs of rat nerve-like cells were isolated by the single-hit method. Such auxotrophic mutants have also been isolated by other methods where temperature-sensitive mutation was utilized and cells were exposed throughout the culture to drugs such as aphidicoline (DNA polymerase inhibitor) (1) or methotrexate (folate reductase inhibitor) (2). Through use of these drugs, the single-hit method can be effectively applied for isolation of thymidine auxotrophs.

The results of growth tests revealed an interesting fact regarding the enzyme thymidylate synthetase. The enzyme activity in B3T cells was below the level of physiological significance because B3T cells were not able to grow in the medium containing pyrazofurin and uridine. However, if an excess of dUMP was present, the enzyme could support the growth of B3T cells, indicating that the catalytic ability of the enzyme in B3T cells must have decreased. Probably, these phenomena are due to lower affinity of the enzyme to the substrate (3) or to decreased production of the enzyme.

Whether the character of thymidine auxotrophs is genetically dominant or recessive is of interest. This question was answered by cell hybridization (submitted for publication). B3T cells were fused with human neuroblastoma cells (IMR-32) (21) and then cell hybrids were obtained. These hybrid cells were able to grow in regular medium without the addition of thymidine.
This finding indicates that the thymidine auxotrophy of $\mathrm{B} 3 \mathrm{~T}$ cells is a genetically recessive trait.

B3T cells had the ability to differentiate and extend neurites in response to exogenously added db-cAMP. It is of interest that the response of B3T cells was faster than that of B103, suggesting that B3T cells may have acquired altered sensitivity to db-cAMP. B3T cells present valuable opportunities for genetic and molecular biological studies of neuronal cells.

Acknowledgements. The author is grateful to Dr. D. Schubert for kindly supplying B103 cells.

\section{REFERENCES}

1. Ayusawa, D., Iwata, K., and Seno, T. (1980). Isolation of mouse FM3A cell mutants with thermolabile thymidylate synthetase by resistance to aphidicolin. Biochem. Biophys. Res. Comm. 96: 1654-1661.

2. Ayusawa, D., Iwata, K., and Seno, T. (1981). Conditional thymidine auxotrophic mutants of mouse FM3A cells due to thermosensitive thymidylate synthetase and their protrophic revertants. J. Biol. Chem. 256: 12005-12012.

3. Bapat, A.R., Zarow, C., and Danenberg, P.V. (1983). Human leukemic cells resistant to 5-fluoro-2'-deoxyruidine contain a thymidylate synthetase with lower affinity for nucleotides. J. Biol. Chem. 258: 4130-4136.

4. Baskin, F., Davis, R., and Rosenberg, R.N. (1977). Altered thymidine kinase or thymidylate synthetase activities in 5 fluorodeoxyuridine resistant variants of mouse neuroblastoma. J. Neurosci. 29: 1031-1037.

5. Chan, T.-S., Meuth, M., and Green, H. (1974). Pyrimidine excretion by cultured fibroblasts: Effects of mutational deficiency in pyrimidine salvage enzymes. J. Cell. Physiol. 83: 263-266.

6. CHU, E.H.Y. and Malling, H.V. (1968). Mammalian cell genetics, II. Chemical induction of specific locus mutations in Chinese hamster cells in vitro. Proc. Natl. Acad. Sci. USA 61: 1306-1312.

7. DENG, T., LI, D., JENH, C.-H., and Johnson, L.F. (1986). Structure of the gene for mouse thymidylate synthetase: Location of introns and multiple transcriptional start sites. J. Biol. Chem. 261: 16000-16005.

8. GEYer, P.K. and Johnson L.F. (1984). Molecular cloning of DNA sequences complementary to mouse thymidylate synthetase messenger RNA. J. Biol. Chem. 259: 7206-7211.

9. Gutowski, G.E., Sweeney, M.J., Delong, D.C., Hamill, R.L., Gerzon, K., and Dyke., R.W. (1975). Biochemistry and biological effects of the pyrazofurins (pyrazomycins): Initial clinical trial. Ann. N.Y. Acad. Sci. 255: 544-551.

10. Ishi, K., Sakamoto, H., Furuyama, J., and Hanaoka, M. (1984). Cytidine deaminase levels in cultured mammalian cell lines measured by the growth tests and enzyme assays. Cell Struct. Funct. 9: 117-123.

11. Jenh, C.-H., Geyer, P.K., Baskin, F., and Johnson, L.F. (1985). Thymidylate synthetase gene amplification in fluorodeoxyuridine-resistant mouse cell lines. Mol. Pharmacol. 28: 8085.

12. Kusano, T., Kato, M., and Yamane, I. (1976). Isolation of uridine requiring variants in Chinese hamster cells. Cell Struct. Funct. 1: 393-396.

13. Mulkins, M.A. and Heidelberger, C. (1982). Biochemical 
characterization of fluoropyrimidine-resistant murine leukemic cell lines. Cancer Res. 42: 965-973.

14. Rode, W., Scanlon, K.J., Hynes, J., and Bertino, J.R. (1979). Purification of mammalian tumor (L1210) thymidylate synthetase by affinity chromatography on stable biospecific adsorbent: Stabilization of the enzyme with neutral detergents. $J$. Biol. Chem. 254: 11538-11543.

15. Rossana, C., Rao, L.G., and Johnson, L.F. (1982). Thymidylate synthetase overproduction in 5-fluorodeoxyuridine-resistant mouse fibroblasts. Mol. Cell. Biol. 2: 1118-1125.

16. SAnTI, D.V. and MCHenry, C.S. (1972). 5-fuoro-2'-deoxyuridylate: Covalent complex with thymidylate synthetase. Proc. Natl. Acad. Sci. USA 69: 1855-1857.

17. Schubert, D., Heinemann, S., Carlisle, W., Tarikas, H., Kimes, B., Patrick, J., Steinbach, J.H., Culp, W., and BRANDT. B.L. (1974). Clonal cell lines from the rat central nervous system. Nature 249: 224-227.

18. Slack, C., Morgan, R.H.M., Carritt, B., Goldfarb, P.S.G., and Hooper, M.L. (1976). Isolation and characterization of Chinese hamster cells resistant to 5-fluorodeoxyuridine. Exp. Cell Res. 98: 1-14.

19. Suttle, D.P. and Stark, G.R. (1979). Coordinate overproduction of orotate phosphoribosyltransferase and orotidine-5'phosphate decarboxylase in hamster cells resistant to pyrazofurin and 6-azauridine. J. Biol. Chem. 254: 4602-4607.

20. Takeishi, K., Kaneda, S., Ayusawa, D., Shimizu, K., Gotoh, O., and Seno, T. (1985). Nucleotide sequence of a function cDNA for human thymidylate synthetase. Nucl. Acid. Res. 13: 2035-2043.

21. Tumilowicz, J.J., Nichols, W.W., Cholon, J.J., and Greene, A.E. (1970). Definition of a continuous human cell line derived from neuroblastoma. Cancer Res. 39: 2110-2118.

22. Ullman, B., Levinson, B.B., Ullman, D.H., and Martin, D.W, JR. (1979). Isolation and characterzation of cultured mouse T-lymphoma cells deficient in uridine-cytidine kinase. $J$. Biol. Chem. 254: 8736-8739.

(Received for publication, November 21, 1989 and in revised form, February 13, 1990) 